\title{
The effect of standing vs. variants of the seated position on lumbar intersegmental angulation and spacing: a radiographic study of 20 asymptomatic subjects
}

\author{
Todd F. Alamin ${ }^{1}$, Vijay Agarwal' ${ }^{2}$ Alicia Zagel ${ }^{3}$, Albi Qeli $^{4}$ \\ ${ }^{1}$ Orthopaedic Surgery, Stanford University School of Medicine, Redwood City, CA, USA; ${ }^{2}$ Division of Neurological Surgery, Department of Surgery, \\ Duke University Medical Center, Durham, NC, USA; ${ }^{3}$ Children's Minnesota Research Institute, Minneapolis, MN, USA; ${ }^{4}$ US Department of \\ Veterans Affairs, Northern California Health Care System, The David Grant USAF Medical Center, Fairfield, CA, USA \\ Contributions: (I) Conception and design: TF Alamin, A Qeli; (II) Administrative support: All authors; (III) Provision of study materials or patients: \\ TF Alamin, A Qeli; (IV) Collection and assembly of data: TF Alamin, A Qeli, V Agarwal; (V) Data analysis and interpretation: All authors; (VI) \\ Manuscript writing: All authors; (VII) Final approval of manuscript: All authors. \\ Correspondence to: Todd F. Alamin, MD. Associate Professor, Orthopaedic Surgery, Stanford University School of Medicine, 300 Pasteur Drive, Room \\ R-171 Stanford, CA 94305, USA. Email: tfalamin@stanford.edu.
}

\begin{abstract}
Background: Pain while sitting is the primary complaint of many patients with lumbar spinal ailments, including those with discogenic low back pain and lumbar disc herniations. There has been little basic research on the different mechanical stresses that different sitting positions place on the spine. To demonstrate the effect of different sitting positions on lumbar intersegmental relationships.

Methods: Twenty healthy male volunteer subjects were recruited. Lateral X-rays of the lower lumbar spine were taken in four positions: (I) relaxed lateral standing; (II) "standard" sitting position; (III) sitting on a "kneeling" chair; and (IV) unsupported sitting on a stool. Anterior and posterior disc height, disc space angulation, L1-S1 angulation and interspinous distance were measured.

Results: The L1-S1 lordotic angle in the standing position $\left(48.8^{\circ} \pm 14.7^{\circ}\right)$ was found to be statistically significantly greater than the angle measured with any of the sitting positions: the kneeling chair $\left(34.0^{\circ} \pm 17.7^{\circ}\right)$; hard-back chair $\left(28.6^{\circ} \pm 14.3^{\circ}\right)$; and the stool $\left(16.6^{\circ} \pm 15.6^{\circ}\right)$. Total average disc height (arithmetic sum of average disc heights L2-S1) in the lumbar spine varied with position: standing $(40.5 \pm 7.75 \mathrm{~mm})$; hard-back chair $(38.5 \pm 6.9 \mathrm{~mm})$; kneeling chair $(38.4 \pm 7.9 \mathrm{~mm})$; stool $(36.9 \pm 7.1 \mathrm{~mm})$. The mean interspinous distance over all the lumbar levels was significantly greater in each of the three seated positions than in the standing position: standing $6.8 \pm 4.5 \mathrm{~mm} ; 11.6^{\circ} \pm 7.5^{\circ}$ for the kneeling chair; $12.9 \pm 5.8 \mathrm{~mm}$ for the hard-back chair; $16.9 \pm 7.0 \mathrm{~mm}$ for the stool. Conclusions: If segmental flexion and segmental loading are the important biomechanical correlates of pain on sitting, such patients should be most comfortable in a kneeling chair, which most closely approximates the standing position. These basic findings will allow better assessment of different seating positions from an ergonomic perspective, and hopefully lead to improvements in chair design.
\end{abstract}

Keywords: Low back pain; lumbar disc herniation; sitting

Submitted Oct 03, 2017. Accepted for publication May 24, 2018.

doi: $10.21037 /$ jss.2018.08.03

View this article at: http://dx.doi.org/10.21037/jss.2018.08.03

\section{Introduction}

Pain while sitting is the primary complaint of many patients with lumbar spinal ailments, including those with discogenic low back pain and lumbar disc herniations $(1,2)$.
These patients typically achieve some degree of relief of their symptoms in the standing position. Compared to the standing position, the sitting position places a flexion moment on the spine-inducing relative segmental lumbar 


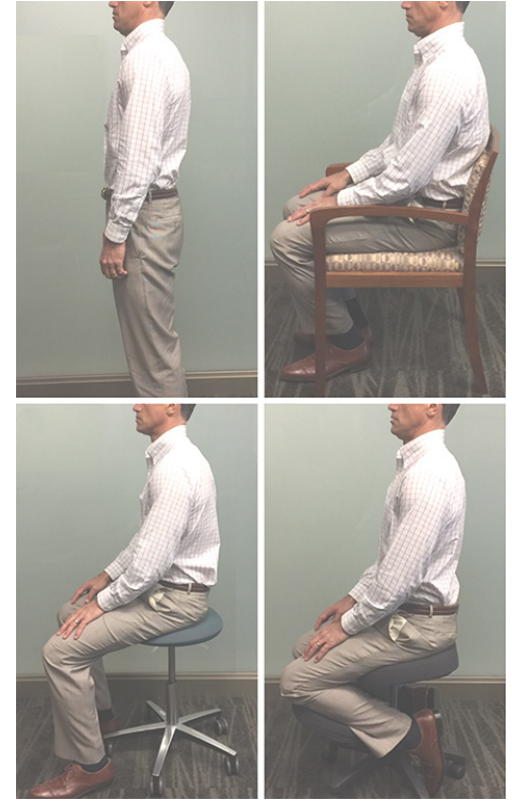

Figure 1 Four different sitting positions.

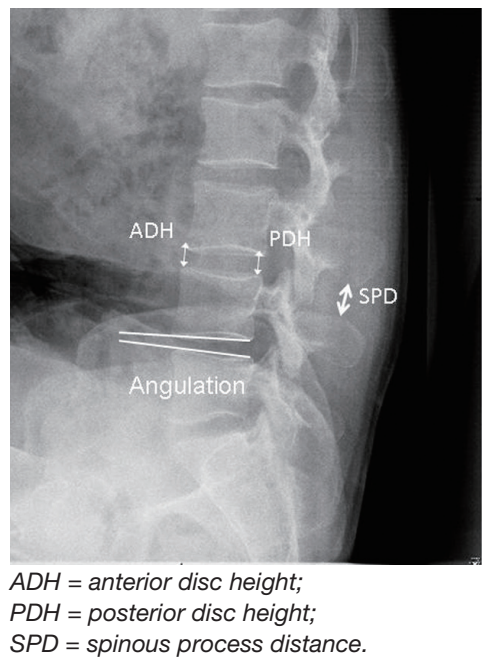

Figure 2 Radiographic measurements.

flexion. This position of segmental flexion has been associated in several different studies with increased loading of the disc (3-7). It has also been associated with posterior translation of the nucleus, and resulting increased strains on the innervated posterior annulus (8).

It is clinically evident that certain sitting positions are worse than others with regards to their propensity to cause significant pain in these patients, but there has been little basic research on the mechanical stresses that different sitting positions place on the spine $(9,10)$. An accurate understanding of the segmental effect on angulation and disc height elicited by different seating positions can be used to estimate forces on the lumbar spine in these different positions. This is of interest not only to patients being treated conservatively for their spinal condition, but also to surgeons interested in minimizing either the loads on spinal instrumentation placed in surgery, or loads on susceptible elements of the postoperative spine.

We undertook this study to examine the intersegmental effect of different sitting positions on the lumbar spines of 20 healthy male volunteers, and to compare it to baseline data obtained in the standing position.

\section{Methods}

Ethical approval from the Stanford University Institutional Review Board and written informed consent from each subject were obtained before the study began. Twenty healthy male volunteer subjects were recruited from the San Francisco/Palo Alto, California area. Mean age was 34.4 years [standard deviation (SD) 12.0 years], mean height $178.8 \mathrm{~cm}$ (SD $9.1 \mathrm{~cm}$ ), and mean weight was $77.6 \mathrm{~kg}$ (SD $10.6 \mathrm{~kg}$ ). Lateral lumbar spine radiographs were obtained in the standing position, and in three distinct sitting positions. Exclusion criteria for the study included female gender (to avoid potential radiation to a fetus in an unknowingly pregnant patient), chronic back pain, radicular pain, or a history of lumbar surgery.

Lateral X-rays of the lower lumbar spine were taken in four positions: (I) relaxed lateral standing; (II) "standard" sitting position on a hard-backed chair; (III) sitting on a commercially available "kneeling" chair; and (IV) unsupported sitting on a stool (Figure 1).

Radiographic data was obtained using the PACS digital imaging system (GE PACS, GE Integrated Imagine Solutions, Mount Prospect, IL, USA). For each radiograph, a standard source-to-film distance of 40 inches was maintained. The primary investigator (Todd F. Alamin) measured anterior and posterior disc height, disc space angulation, L1-S1 angulation and interspinous distance (Figure 2). Average disc height was calculated as the arithmetic average of the anterior and posterior disc heights. To eliminate the effect of source-to-film distance variation on image magnification, the midline L4 vertebral body height was measured for all subjects and used to normalize measurements on different radiographs in the same subject. 
A

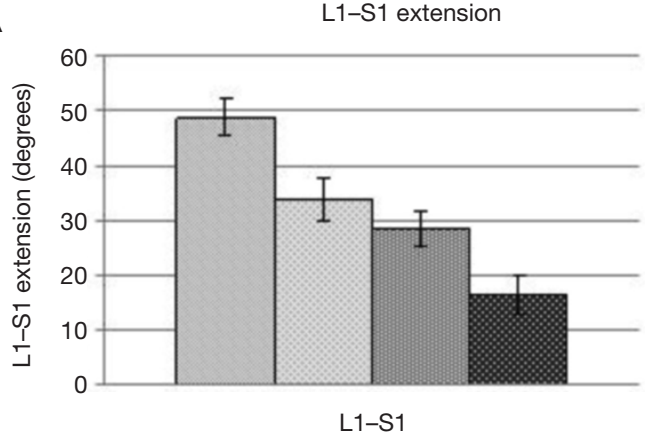

B

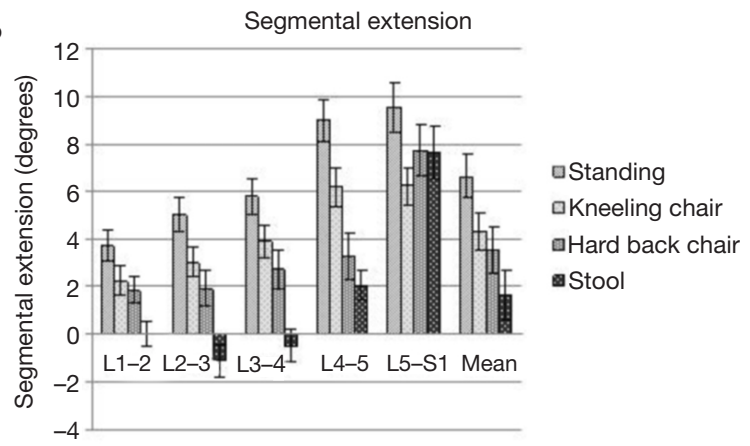

Figure 3 Effect of different sitting positions on (A) L1-S1 lordotic angle and (B) segmental lordosis.

\section{Statistical methods}

To assess radiographic variables, a repeated measure analysis of variance (ANOVA) was used, and Tukey's HSD post hoc pairwise comparisons were calculated. An alpha less than or equal to $0.2 \%$ was considered statistically significant $(\mathrm{P} \leq 0.002)$ to account for a Bonferroni correction to the type I error. Statistical analysis included comparisons of standing and sitting using lordotic angle (L1-S1, L4-L5, L5-S1), posterior disc height (L4-L5, L5-S1), average disc height (L2-S1, L4-L5, L5-S1), interspinous distance (L1-S1, L4L5, L5-S1).

\section{Results}

The L1-S1 lordotic angle in the standing position $\left(48.8^{\circ} \pm 14.7^{\circ}\right)$ was found to be statistically significantly greater than that measured in any of the sitting positions: the kneeling chair $\left(34.0^{\circ} \pm 17.7^{\circ}\right)$, hard-back chair $\left(28.6^{\circ} \pm 14.3^{\circ}\right)$, and the stool $\left(16.6^{\circ} \pm 15.6^{\circ}\right)$. In each of these sitting positions, except when comparing the hard-back chair to the kneeling chair, the L1-S1 lordotic angle was statistically distinct (Figure 3A).

At the L4-5 level, lordotic angulation on both the hard-back chair $\left(3.3^{\circ} \pm 4.4^{\circ}\right)$ and the stool $\left(2.0^{\circ} \pm 2.8^{\circ}\right)$ were statistically less than that measured in the standing position $\left(9.0^{\circ} \pm 3.8^{\circ}\right)$. Angulation at L4-5 measured on the kneeling chair $\left(6.2^{\circ} \pm 3.8^{\circ}\right)$ was not statistically different than the standing position. Statistically different angulation between the positions at the L5-S1 level was not detected. The effect of the different positions on segmental angulation is depicted in Figure 3.

Posterior disc height averaged over all tested levels, L2$\mathrm{S} 1$, for the hard-back chair $(8.2 \pm 2.4 \mathrm{~mm})$ and the stool $(8.4 \pm 2.2 \mathrm{~mm})$ was statistically greater than that recorded in the standing position $(7.5 \pm 1.8 \mathrm{~mm})$. At the $\mathrm{L} 4-5$ level, mean posterior disc heights on the hard-back chair $(8.8 \pm 3.3 \mathrm{~mm})$, kneeling chair $(8.3 \pm 1.9 \mathrm{~mm})$, and the stool $(8.4 \pm 2.3 \mathrm{~mm})$ were not statistically significantly greater than the mean posterior disc height in the standing position $(7.6 \pm 1.6 \mathrm{~mm})$. At the L5-S1 level, a similar trend was found that was not statistically significant: standing position $(7.0 \pm 1.5 \mathrm{~mm})<$ kneeling chair $(7.2 \pm 1.4 \mathrm{~mm})$, hard-back chair $(7.2 \pm 1.5 \mathrm{~mm})<\operatorname{stool}(7.7 \pm 2.5 \mathrm{~mm})$. A similar trend in the opposite direction between the positions were noted on measurement of the anterior disc height-the mean anterior heights were greater in the standing position than in the seated positions (Figure 4).

Total average disc height (arithmetic sum of average disc heights L2-S1) in the lumbar spine $(\mathrm{n}=17)$ varied with position: standing $(40.5 \pm 7.7 \mathrm{~mm})>$ hard-back chair $(38.5 \pm 6.9 \mathrm{~mm})>$ kneeling chair $(38.4 \pm 7.9 \mathrm{~mm})>$ stool $(36.9 \pm 7.1 \mathrm{~mm})$; only the difference between the stool and the standing position represented a statistically significant difference $(\mathrm{P}=0.002)$ (Figure 5). Average disc height at the L4-5 and L3-4 levels varied significantly more with position than the other lumbar levels $(\mathrm{P}<0.01)$.

The mean interspinous distance over all the lumbar levels was significantly greater in each of the three seated positions than in the standing position: standing $6.8 \pm 4.5 \mathrm{~mm}$; $11.6^{\circ} \pm 7.5^{\circ}$ for the kneeling chair; $12.9 \pm 5.8 \mathrm{~mm}$ for the hard-back chair; $16.9 \pm 7.0 \mathrm{~mm}$ for the stool. At the L4-5 level, the seated interspinous distance was significantly greater than the standing interspinous distance for all three seated positions: standing $(4.5 \pm 2.5 \mathrm{~mm})$, kneeling chair $(10.0 \pm 6.1 \mathrm{~mm})$, hard-back chair $(13.3 \pm 7.0 \mathrm{~mm})$ and stool $(16.0 \pm 7.8 \mathrm{~mm}$. No significant differences were detected at the L5-S1 segment amongst the different positions, but again, the same trend was observed: stool $(14.5 \pm 4.7 \mathrm{~mm})>$ hard-back chair $(13.3 \pm 2.2 \mathrm{~mm})>$ kneeling 
A

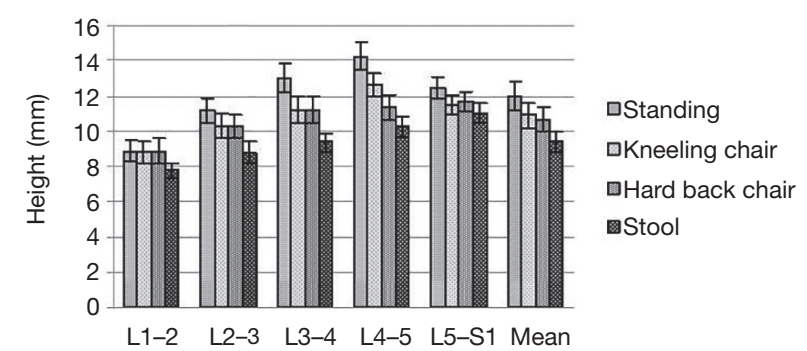

B

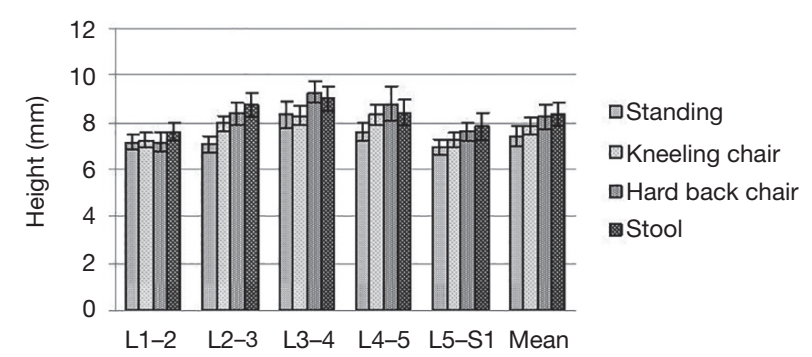

Figure 4 Effect of different sitting positions on (A) anterior disc height and (B) posterior disc height.

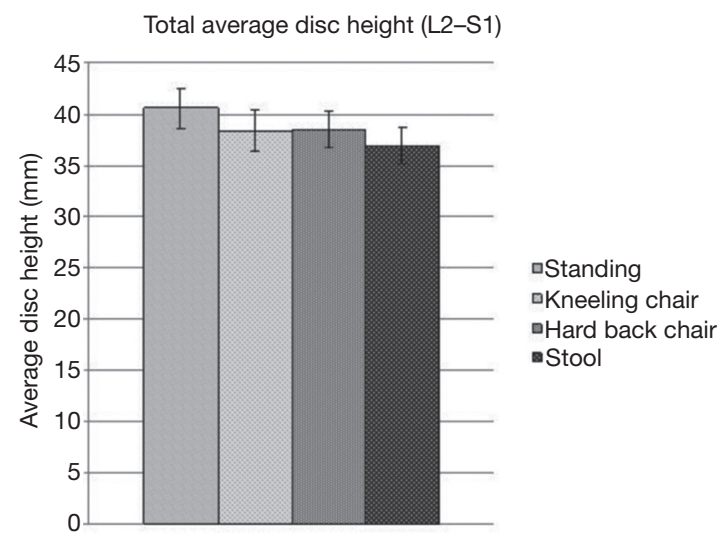

Figure 5 Effect of different sitting positions on total disc height.

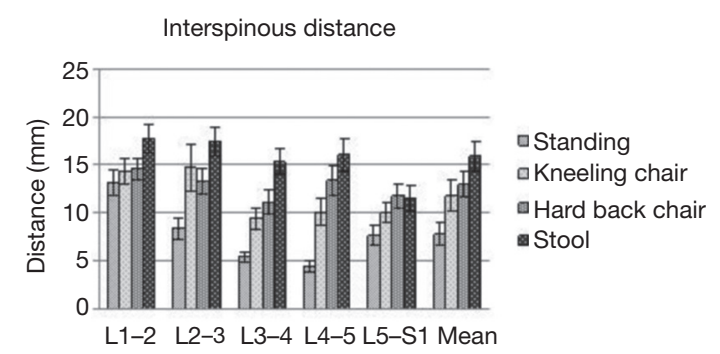

Figure 6 Effect of different sitting positions on interspinous distance.

chair $(11.4 \pm 3.3 \mathrm{~mm})>$ standing $(4.9 \pm 3.6 \mathrm{~mm})$ (Figure 6).

\section{Discussion}

Pain while sitting is an important clinical complaint for patients with several different spinal disorders, including discogenic low back pain and lumbar disc herniation $(11,12)$. This is not a uniform complaint, however, and is typically one that is affected by the specific sort of chair in which the patient is sitting. For instance, chairs having a forward-inclined seat-pan seem only to reduce low back pain discomfort with flexion-related pain (13), and not with extension-related pain (14). Chairs that put an individual in a semi-kneeling position have been shown to increase pedal cutaneous blood flow in subjects over traditional chairs, though participants of that study indicated they preferred to sit in traditional chairs (15). Further, sitting in chairs with backrests have been found to reduce paraspinal muscle activation, not necessarily reduce low back pain (16). More recently, radiographic evidence has supported the idea that using a chair with back support, can minimize changes to lumbar lordosis and pelvic parameters that occur between sitting and standing (17), but this study did not assess the results of using a kneeling chair.

Since Americans spend, on average, close to 8 hours a day in sedentary behaviors (18), it is crucial to find methods to reduce lifestyle-related low back pain. We performed this radiographic study in healthy male volunteers to better understand the intersegmental effect of sitting compared to standing at different levels of the lumbar spine, and further examine the relative effect of different sitting positions on these parameters.

In this investigation, we found that the different positions that were examined had differential effects on segmental angulation and disc height. The standing position elicited the most segmental extension as measured by the L1-S1 lordotic angle as well by measurements of individual levels of the lumbar spine, followed by the kneeling chair, the hard-back chair, and then the stool. The inverse order was seen on examination of posterior disc height and interspinous distance: stool > hard-back chair > kneeling chair $>$ standing position. It should be noted that these other variables that were measured would be expected to, by virtue of the biomechanics of the spine, vary in this way with segmental angulation, and that with the numbers 
available here, we did not detect any significant variances from this expected linkage. This variability in angle, disc height, and interspinous distance was differentially exhibited across different lumbar levels, with the L5-S1 disc changing the least between positions. There are several potential reasons for these findings of least variability at the L5/S1 level compared to other lumbar levels, such as the more deeply-seated position of the L5-S1 disc within the pelvis and the broader attachment of the L5/S1 interspinous ligaments to the sacral ala, along with the broader and more coronal morphology of the L5/S1 facet joints.

There are several limitations of this study that limit its potential generalizability. Our sample size of 20 healthy male volunteers was small, and the age range was relatively young (mean age 34 ). The chairs that were used were chosen to be representative of types of seated positions, but clearly there are a wide variety of commercially available chair types with multiple types of seat and back configurations, in many cases adjustable, that were not fully modeled here. It would be interesting to explore this investigation further with a larger number of subjects with a wider age range, and perhaps different sorts of seating arrangements that would allow us to determine the isolated effect, for example, of changes in the seat configuration, the back support, and perhaps the addition of the tibial support in different positions, but this was beyond the scope of this project.

The amount of increase in flexion seen in the change between standing and the different seated positions represented a significant percentage of the typical total range of motion values given for total sagittal plane angular motion at these disc levels. The total flexion/extension range of motion on three different articles that have assessed this parameter has an average value of $16^{\circ}$ at $\mathrm{L} 4-5$, and $15^{\circ}$ at L5-S1 (19-21). Approximately $75 \%$ of this arc of motion occurs between standing and full flexion, and $25 \%$ between standing and full extension (21). The mean change from the standing position to sitting in the kneeling chair represented $25 \%$, in the hard-back chair $50 \%$, and in the stool, $58 \%$ of the average total arc of flexion at L4/5 beyond the standing position. A mean of $15^{\circ}$ of flexion was measured across L1-S1 when changing from the standing position to the kneeling chair, $20^{\circ}$ of flexion from the standing position to the hard-back chair, and $32^{\circ}$ of flexion from the standing position to the stool.

Flexion of the lumbar segment affects the way that it bears load in several significant ways that may explain the characteristic nature of pain with sitting in certain spinal conditions. Flexion of the segment affects the segmental load distribution between the facets and the disc such that it has been reported that in the flexed position of approximately neutral $\left(0^{\circ}\right)$ and a moderate preload of 400 $\mathrm{N}$, the facet joints bear $10 \%$ of the axial load, whereas in $6-8^{\circ}$ of lordosis (roughly the standing position) and similar preload, the facet joints bear $32 \%$ of the axial load (22). Flexion of the lumbar spine also changes the relationship of the center of mass of the body and the spinal column such that in flexion, the flexion moment on the spine is increased, and loads seen at the level of the disc given a constant body weight are increased.

Several authors have found that in vivo disc pressure, a proxy for directly measuring loads across the disc, is higher in the sitting position than in the standing position $(3,4)$. However, two more recent articles have found disc pressures to be lower in the relaxed sitting position than in the standing position, and have also found that sitting with "good posture" by activating the truncal supporting musculature in fact increases the measured disc pressure $(5,23)$. These more recent reports suffer from small sample size, but call into question the assumption that in a patient with discogenic pain, disc pressure is the important variable to follow that correlates with the symptom of pain.

We were able to measure average disc height, an alternate method of estimating segmental loads on the spine, in the different positions examined here. We found that total average disc height in the lumbar spine was greatest in the standing position $(40.5 \pm 7.7 \mathrm{~mm})$, followed by the hard-back chair $(38.5 \pm 6.9 \mathrm{~mm})$, the kneeling chair $(38.4 \pm 7.9 \mathrm{~mm})$, and then the stool $(36.9 \pm 7.1 \mathrm{~mm})$. One would expect that average disc height would vary indirectly with segmental loads and intradiscal pressure, and so this finding corroborates the findings of Nachemson and others who have reported higher intradiscal loads in the seated position compared to the standing position, and stands in contrast to the findings of Wilke and others, who have reported higher loads in the standing compared to relaxed sitting positions.

The other significant effect of segmental flexion is on the position of nuclear material: as the segment flexes, there is bulk flow of the nucleus posteriorly, and this posterior movement at the level of a lumbar disc herniation may increase the compression of an affected nerve root by the disc herniation. In the case of discogenic back pain, increased strains on the innervated posterior annulus in the flexed position may be enough to exacerbate the complaint of back pain. 
The different seating positions examined here create different segmental relationships in the lumbar spine because of the effect on hip flexion, and also through the way in which the load of the body is transferred to the chair. In the standing position, the hips are maintained in extension, which rotates the pelvis forward in the sagittal plane (increased pelvic inclination), and as the upper trunk stays balanced over the pelvis, rotates the lumbar spine into extension. In the two standard sitting positions (stool and hard backed chair), the hips are flexed, flexing the pelvis (decreased pelvic inclination). The load of the body in these positions is transferred to the chair through the ischial tuberosities and proximal femurs, both anterior to the lumbar spine in the sagittal plane with the hips in flexionthis places a flexion moment on the spine, increasing lumbar segmental flexion. The hard-back chair may allow less flexion than the stool without a back as the propensity of the pelvis to rotate in this position of hip flexion is limited by the chair back. The kneeling chair, by contrast, places the hips in approximately $45^{\circ}$ of flexion, and thereby causes the pelvis to flex less than the other seated positions. It also transfers load to the chair through the knees and axially through the femurs instead of entirely through the ischial tuberosities and proximal femurs; this involves a loading pattern through the hips that is more similar to the standing position.

\section{Conclusions}

It is hoped that a better understanding of the spinal loading characteristics of different seating positions may lead to both a better understanding of the reasons leading to the common clinical complaint of pain with sitting, and improvements in chair design that may lead to more comfortable seating conditions for such patients. We have found here significant flexion of the lumbar spine in the seated compared with the standing position in healthy male subjects, and noted this to be greatest on an unsupported stool, intermediate on a hard-backed chair, and least on a kneeling chair. We have also found that average disc height, a secondary indicator of segmental loads, is least on a stool, and of the positions examined here, greatest in the standing position. If segmental flexion and segmental loading are the important biomechanical correlates of pain on sitting that are characteristic of both discogenic pain and lumbar disc herniation, we would expect that these patients would be most comfortable in a kneeling chair, which most closely approximates the standing position, and least comfortable on an unsupported stool.

Follow-up studies involving greater sample sizes and age range distributions with evaluation of anteroposterior radiographs, or MRI scanning in different seated positions will further add to our understanding of both the spinal biomechanics of sitting as well as mechanism of pain in these different clinical conditions.

\section{Acknowledgements}

This study was supported by a grant from Synthes Spine, LLC.

\section{Footnote}

Conflicts of Interest: The authors have no conflicts of interest to declare.

Ethical Statement: The study was approved by the Stanford University IRB (approval \#8356), and written informed consent from each subject were obtained before the study began.

\section{References}

1. Bell GR. Implications of the Spine Patient Outcomes Research Trial in the clinical management of lumbar disk herniation. Cleve Clin J Med 2007;74:572, 575-6.

2. Dankaerts W, O'Sullivan P, Burnett A, et al. Differences in sitting postures are associated with nonspecific chronic low back pain disorders when patients are subclassified. Spine (Phila Pa 1976) 2006;31:698-704.

3. Andersson BJ, Ortengren R, Nachemson AL, et al. The sitting posture: an electromyographic and discometric study. Orthop Clin North Am 1975;6:105-20.

4. Nachemson AL. Disc pressure measurements. Spine (Phila Pa 1976) 1981;6:93-7.

5. Rohlmannt A, Claes LE, Bergmannt G, et al. Comparison of intradiscal pressures and spinal fixator loads for different body positions and exercises. Ergonomics 2001;44:781-94.

6. Shirazi-Adl A. Biomechanics of the lumbar spine in sagittal/lateral moments. Spine (Phila Pa 1976) 1994;19:2407-14.

7. Shirazi-Adl A, Drouin G. Load-bearing role of facets in a lumbar segment under sagittal plane loadings. J Biomech 1987;20:601-13.

8. White AA, Panjabi MM. Clinical biomechanics of the spine. Second Edition, 1991.

9. Hedman TP, Fernie GR. Mechanical response of the 
lumbar spine to seated postural loads. Spine (Phila $\mathrm{Pa}$ 1976) 1997;22:734-43.

10. O'Sullivan P, Dankaerts W, Burnett A, et al. Lumbopelvic kinematics and trunk muscle activity during sitting on stable and unstable surfaces. J Orthop Sports Phys Ther 2006;36:19-25.

11. Gupta N, Christiansen CS, Hallman DM, et al. Is objectively measured sitting time associated with low back pain? A cross-sectional investigation in the NOMAD study. PLoS One 2015;10:e0121159.

12. Lis AM, Black KM, Korn H, et al. Association between sitting and occupational LBP. Eur Spine J 2007;16:283-98.

13. O'Keeffe M, Dankaerts W, O'Sullivan P, et al. Specific flexion-related low back pain and sitting: comparison of seated discomfort on two different chairs. Ergonomics 2013;56:650-8.

14. Curran M, Dankaerts W, O'Sullivan P, et al. The effect of a backrest and seatpan inclination on sitting discomfort and trunk muscle activation in subjects with extensionrelated low back pain. Ergonomics 2014;57:733-43.

15. Lander C, Korbon GA, DeGood DE, et al. The Balans chair and its semi-kneeling position: an ergonomic comparison with the conventional sitting position. Spine (Phila Pa 1976) 1987;12:269-72.

16. Curran M, O'Sullivan L, O'Sullivan P, et al. Does Using a Chair Backrest or Reducing Seated Hip Flexion Influence Trunk Muscle Activity and Discomfort? A Systematic

Cite this article as: Alamin TF, Agarwal V, Zagel A, Qeli A. The effect of standing $v s$. variants of the seated position on lumbar intersegmental angulation and spacing: a radiographic study of 20 asymptomatic subjects. J Spine Surg 2018;4(3):509515. doi: $10.21037 /$ jss.2018.08.03
Review. Hum Factors 2015;57:1115-48.

17. Cho IY, Park SY, Park JH, et al. The Effect of Standing and Different Sitting Positions on Lumbar Lordosis: Radiographic Study of 30 Healthy Volunteers. Asian Spine J 2015;9:762-9.

18. Matthews CE, Chen KY, Freedson PS, et al. Amount of time spent in sedentary behaviors in the United States, 2003-2004. Am J Epidemiol 2008;167:875-81.

19. Dvorak J, Panjabi MM, Chang DG, et al. Functional radiographic diagnosis of the lumbar spine. Flexionextension and lateral bending. Spine (Phila $\mathrm{Pa} 1976$ ) 1991;16:562-71.

20. Hayes MA, Howard TC, Gruel CR, et al. Roentgenographic evaluation of lumbar spine flexionextension in asymptomatic individuals. Spine (Phila $\mathrm{Pa}$ 1976) 1989;14:327-31.

21. Pearcy M, Portek I, Shepherd J. Three-dimensional x-ray analysis of normal movement in the lumbar spine. Spine (Phila Pa 1976) 1984;9:294-7.

22. Lorenz M, Patwardhan A, Vanderby R Jr. Loadbearing characteristics of lumbar facets in normal and surgically altered spinal segments. Spine (Phila Pa 1976) 1983;8:122-30.

23. Wilke HJ, Neef P, Caimi M, et al. New in vivo measurements of pressures in the intervertebral disc in daily life. Spine (Phila Pa 1976) 1999;24:755-62. 